\title{
Mengukur Tingkat Kematangan Penggunaan Sumber Daya Sistem Informasi Pada Rumah Sakit
}

\author{
Friska Aryani, Hasmawaty \& Widya Cholil \\ Universitas Bina Darma \\ Email:aryanifrizka@yahoo.com
}

\begin{abstract}
The information system is very important in operational activities at RSIA Hamami. The purpose of evaluating the use of information system resources at RSIA Hamami is to measure the performance of the information system with the services provided by RSIA Hamami. The method used in evaluating is COBIT 5.0 , the method used is descriptive quantitative with a research instrument in the form of a questionnaire. The focus in this study uses several COBIT 5.0 domains including EDM04, APO09, DSS02, MEA01. The result of this research is that the overall maturity level of RSIA Hamami is still at level 3. In the EDM04 domain, the maturity level obtained is 3.54. In the APO09 domain, the maturity level obtained is 3.48 . In the DSS02 domain, the maturity level obtained was 3.20. In the MEA01 domain, the maturity level obtained is 3.24. From the results of the evaluation obtained, it can make RSIA Hamami more focused on improving the performance of the use of information system resources on the part that needs special attention. Through the COBIT 5.0 method, RSIA Hamami can see which parts of the hospital are still less than optimal, so that they can further develop and be able to provide the best service for patients in accordance with the vision and mission of RSIA Hamami.
\end{abstract}

Keywords: COBIT 5.0, RSIA Hamami, information systems.

\section{Pendahuluan}

Perkembangan sistem informasi saat ini sangat cepat, khususnya pada suatu instansi atau organisasi yang sangat membutuhkan suatu informasi untuk pengambilan keputusan. Salah satu sektor kehidupan manusia yang paling banyak memanfaatkan sistem informasi adalah organisasi, baik organisasi yang berorientasi bisnis atau profit maupun nonprofit. Pemanfaatan ini tidak hanya berfungsi sebagai sarana pendukung untuk meningkatkan kinerja, namun lebih dari itu merupakan sarana utama untuk memenangkan persaingan yang semakin kompetitif. Salah satu kebutuhan yang sangat penting bagi suatu organisasi saat ini adalah sistem informasi, karena dengan adanya sistem informasi dapat membantu perusahaan dalam meningkatkan efisiensi dan efektifitas dari proses bisnis perusahaan itu sendiri. Cara baru dalam menggunakan sistem informasi telah digunakan oleh banyak perusahaan sebagai salah satu solusi dalam menghadapi dan memenangkan persaingan. Untuk mencapai tujuan tersebut dibutuhkan perencanaan, implementasi, dukungan, wawasan, pengawasan dan evaluasi yang matang dan optimal. Sehingga mengurangi resiko akan terjadinya kerugian yang banyak terjadi dari kehilangan data, penyalahgunaan data, informasi yang tidak akurat.Evaluasi sistem meliputi evektifitas sistem dan efesiensi sistem mengacu pada kinerja sistem secara teknis misalnya kecepatan akses data, waktu downline, integritas data dan sejenisnya, sedangkan evaluasi evektifitas mengukur sejauh mana sistem dapat memenuhi kebutuhan organisasi.

Evaluasi merupakan salah satu aspek penting yang diperlukan untuk menentukan keberhasilan implementasi suatu sistem informasi. Melalui evaluasi kita dapat

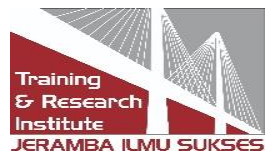


memperoleh informasi mengenai sejauh mana keberhasilan mencapai tujuan sistem tersebut dan juga umpan balik untuk meningkatkan kualitas sistem dimasa yang akan datang untuk menjaga agar sistem tersebut dapat diandalkan dan dapat dipercaya maka perlu evaluasi sistem informasi supaya menghasilkan informasi yang lebih relevan, tepat waktu, akurat, dan lengkap.

RSIA Hamami adalah rumah sakit swasta yang resmi didirikan pada tanggal 28 januari

2010 oleh Kepala Dinas Kesehatan Kota Palembang yang telah mengizinkan Dr. Mustofa Husin Syahab, Sp.OG selaku pimpinan rumah sakit untuk membuka layanan kesehatan. RSIA Hamami merupakan rumah sakit yang telah memanfaatkan peranan sistem informasi dalam proses operasionalnya. Setiap divisi pada RSIA Hamami dipasang aplikasi hospital information system pada divisi administrasi, divisi server sebagai penampung database, dan pada apotek dipasang aplikasi sistem informasi apotek dan semua sistem saling terhubung. Tetapi disisi yang lain terdapat masalah yang sering terjadi didalam penggunaan sistem tersebut yaitu, keterlambatan data, penumpukan data, data hilang, data rusak, dan jaringan internet tidak tersedia. Maka dengan alasan tersebut maka penulis memilih RSIA Hamami sebagai objek penelitian dalam evaluasi untuk mengukur kinerja penggunaan sumber daya sistem informasi pada RSIA Hamami terhadap layanan kesehatan yang telah diberikan.

Salah satu acuan yang dapat digunakan untuk mengukur penerapan sistem informasi adalah Control Objectives for Information and Related Technology (COBIT). Berdasarkan dari latar belakang yang telah diuraikan diatas, penulis tertarik untuk meneliti: "Mengukur Tingkat Kematangan Pada Penggunaan Sumber Daya Sistem Informasi Pada Rumah Sakit".

Berdasarkan latar belakang masalah diatas maka peneliti merumuskan masalah dalam penelitian ini sebagai berikut :

1. Domain apa saja yang dibutuhkan untuk mengevaluasi tingkat kematangan pada RSIA Hamami?

2. Bagaimanakah tingkat kematangan sistem informasi pada RSIA Hamami menggunakan kerangka kerja COBIT 5.0?

\section{Literature Review}

\subsection{Definisi Sistem Informasi}

Definisi sistem informasi yang telah di temukan oleh para ahli diantaranya :

Menurut Jogiyanto sistem informasi adalah suatu kegiatan dari prosedur-prosedur yang diorganisasikan, bilamana dieksekusi akan menyediakan informasi untuk mendukung pengambilan keputusan dan pengendalian di dalam organisasi (Jogiyanto, 1999).

Menurut Abdul Kadir sistem informasi merupakan sekumpulan elemen-elemen atau komponen yakni manusia, komputer, teknologi informasi dan prosedur kerja, ada sesuatu yang diproses (data menjadi informasi), dan dimaksudkan untuk mencapai

suatu sasaran atau tujuan (Kadir, 2003).

\subsection{Pengertian COBIT}

Control objective for Information \& Related Technology (COBIT) adalah sekumpulan dokumentasi best practice untuk IT Governance yang dapat membantu auditor, pengguna (user), dan manajemen, untuk menjembatani gap antara resiko bisnis, kebutuhan kontrol

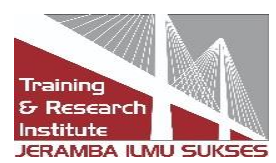




\section{(蟭 JPSII}

dan masalah-masalah teknis IT (Sasongko, 2009).

COBIT muncul pertama kali pada tahun 1996 yaitu COBIT versi 1 yang menekankan pada audit, COBIT versi 2 pada tahun 1998 yang menekankan pada taha pengendalian, COBIT versi 3 pada tahun 2000 yang berorientasi kepada manajemen, COBIT versi 4 pada bulan desember 2005 dan versi 4.1 pada bulan mei 2007 lebih mengarah pada tata kelola TI, dan terakhir COBIT versi 5 pada bulan juni 2012 yang menekankan tata kelola TI pada perusahaan (www.isaca, 2012).

COBIT 5 terdiri dari 5 prinsip utama untuk tata kelola dan manajemen dari sebuah perusahaan yang berbasis IT. Adapun kelima prinsip itu :

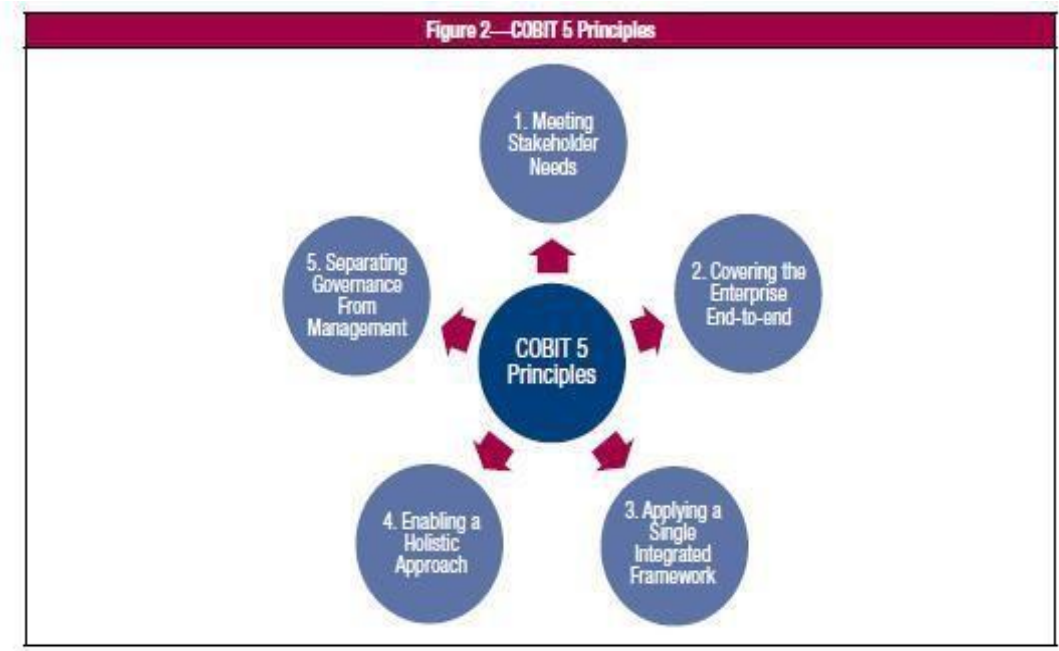

Sumber: ISACA 2012 p.13

Gambar 1. Lima Prinsip COBIT

Penjelasan dari Gambar 1 :

1. Prinsip pertama: meeting stakeholder needs.

Eksistensi perusahaan untuk mewujudkan sebuah nilai bagi stakeholder dengan cara memelihara keseimbangan antara realisasi dari benefit dan optimalisasi menghindari resiko dan penggunaan dari sumber daya. COBIT 5 menyediakan semua proses dan enabler yang dibutuhkan untuk mendukung bisnis dalam menciptakan nilai melalui penggunaan teknologi informasi. Karena setiap perusahaan mempunyai tujuan yang berbeda-beda, maka COBIT 5 dapat dikustomisasi sesuai dengan kebutuhan perusahaan tersebut melalui goals cascade, menterjemahkan high level tujuan perusahaan ke tujuan yang dapat di manajemen, spesifik dan berhubungan dengan IT dan memetakan tujuan tersebut ke proses yang spesifik dan dapat dipraktekkan.

2. Prinsip kedua : covering the enterprise end-to-end .

COBIT 5 mengintegrasikan tata kelola TI Perusahaan ke dalam tata kelola perusahaan dengan cara sebagai berikut : COBIT 5 mencover semua fungsi dan proses didalam

sebuah perusahaan. COBIT 5 tidak hanya fokus pada fungsi TI tetapi juga memperlakukan informasi dan yang berhubungan dengan teknologi sebagai aset yang

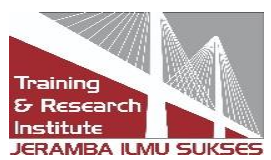


perlu diperlakukan seperti aset sebagaima aset lainnya oleh orang-orang diperusahaan. COBIT 5 mempertimbangkan semua enablers yang berhubungan dengan tata kelola

dan manejemen TI untuk menjadi enterprisewide dan end-to-end. Termasuk juga semua orang dan lainnya baik internal maupun eksternal yang relevan dengan tata kelola dan manajemen perusahaan yang berhubungan dengan TI.

\section{Prinsip ketiga : applying a single, integrated framework.}

Terdapat banyak standar dan pedoman TI yang ada, setiap standar dan pedoman tersebut menyediakan pedoman untuk subset dari aktivitas TI. COBIT 5 menyelaraskan dengan standar dan pedoman lainnya pada tingkat tinggi dan bisa bekerja sebagai pedoman keseluruhan dari standar-standar tersebut

\section{Prinsip keempat : enabling a holistic approach.}

Membuat tata kelola dan manajemen yang efektif dan efisien dibutuhkan sebuah pendekatan yang menyeluruh dengan mempertimbangkan komponen-komponen yang berinteraksi. COBIT 5 mendefinisikan sebuah set enablers untuk mendukung implementasi dari sebuah tata kelola dan sistem manajemen yang komprehensiv untuk sebuah perusahaan. Enablers dapat didefinisikan sebagai sesuatu yang dapat menolong perusahaan untuk mencapai tujuan yang ingin dicapai perusahaan tersebut. Framework COBIT 5 mendefinisikan tujuh kategori dari enablers :

a. Prinsip, kebijakan dan kerangka Kerja

b. Proses

c. Struktur organisasi

d. Kultur, etik dan perilaku

e. Informasi

f. Services, infrastruktur dan aplikasi

g. Orang, skil dan kompentensi.

\section{Prinsip kelima : separating governance from management}

Framework COBIT 5 membuat perbedaan yang jelas antara tata kelola dan manajemen. Kedua disiplin ini mencakup perbedaan tipe aktivitas, membutuhkan struktur organisasi yang berbeda dan mempunyai tujuan pelayanan yang berbeda.

Alur tujuan dalam COBIT 5 adalah suatu mekanisme untuk menerjemahkan kebutuhan stakeholder menjadi tujuan-tujuan spesifik pada setiap tingkatan dan setiap area perusahaan dalam mendukung tujuan utama perusahaan dan memenuhi kebutuhan stakeholder, dan hal ini secara efektif mendukung keselarasan antara kebutuhan perusahaan dengan solusi dan layanan TI. Langkah-langkah dalam menentukan goal cascade pada COBIT 5 digambarkan : 


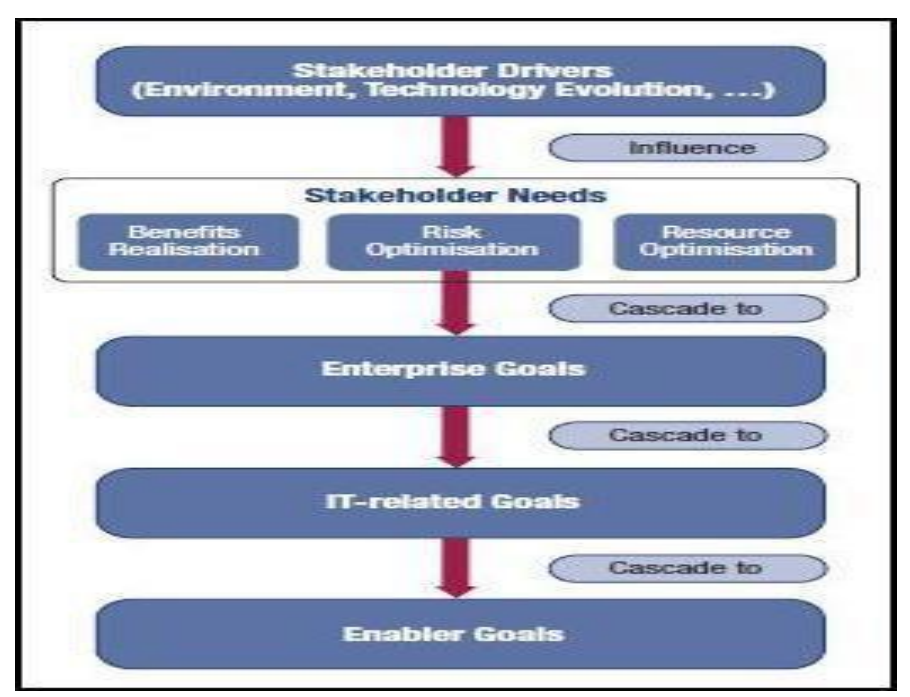

Sumber: ISACA 2012 p.14

Gambar 2. Goals Cascade Overview

Langkah 1. Stakeholder Drivers

Kebutuhan stakeholder dipengaruh oleh sejumlah penggerak, diantaranya perubahan strategi, lingkungan bisnis dan lingkungan yang berubah, dan munculnya teknologi baru.

\section{Langkah 2. Stakeholder Needs}

Kebutuhan stakeholder dapat berhubungan dengan diturunkan menjadi tujuan perusahaan. Tujuan perusahaan tersebut telah dikembangkan menggunakan dimensi Balanced Scorecard (BSC), dan BSC tersebut merepresentasikan sebuah daftar tujuan yang umum digunakan dimana sebuah perusahaan dapat mendefinisikan untuk dirinya sendiri. Meskipun daftar tersebut tidak lengkap menyeluruh, kebanyakan tujuan-tujuan perusahaan tertentu dapat dipetakan secara mudah menjadi satu atau lebih tujuan umum perusahaan. 
COBIT 5 mendefinisikan 17 tujuan umum seperti dapat dilihat pada tabel berikut :

a) Dimensi BSC dimana cocok untuk tujuan perusahaan

b) Hubungan dengan realisasi tiga pemerintahan tujuan-tujuan utama, optimasi risiko dan sumber daya optimasi. ('P' adalah singkatan dari hubungan primer dan ' $S$ ' untuk hubungan sekunder yaitu, hubungan kurang kuat).

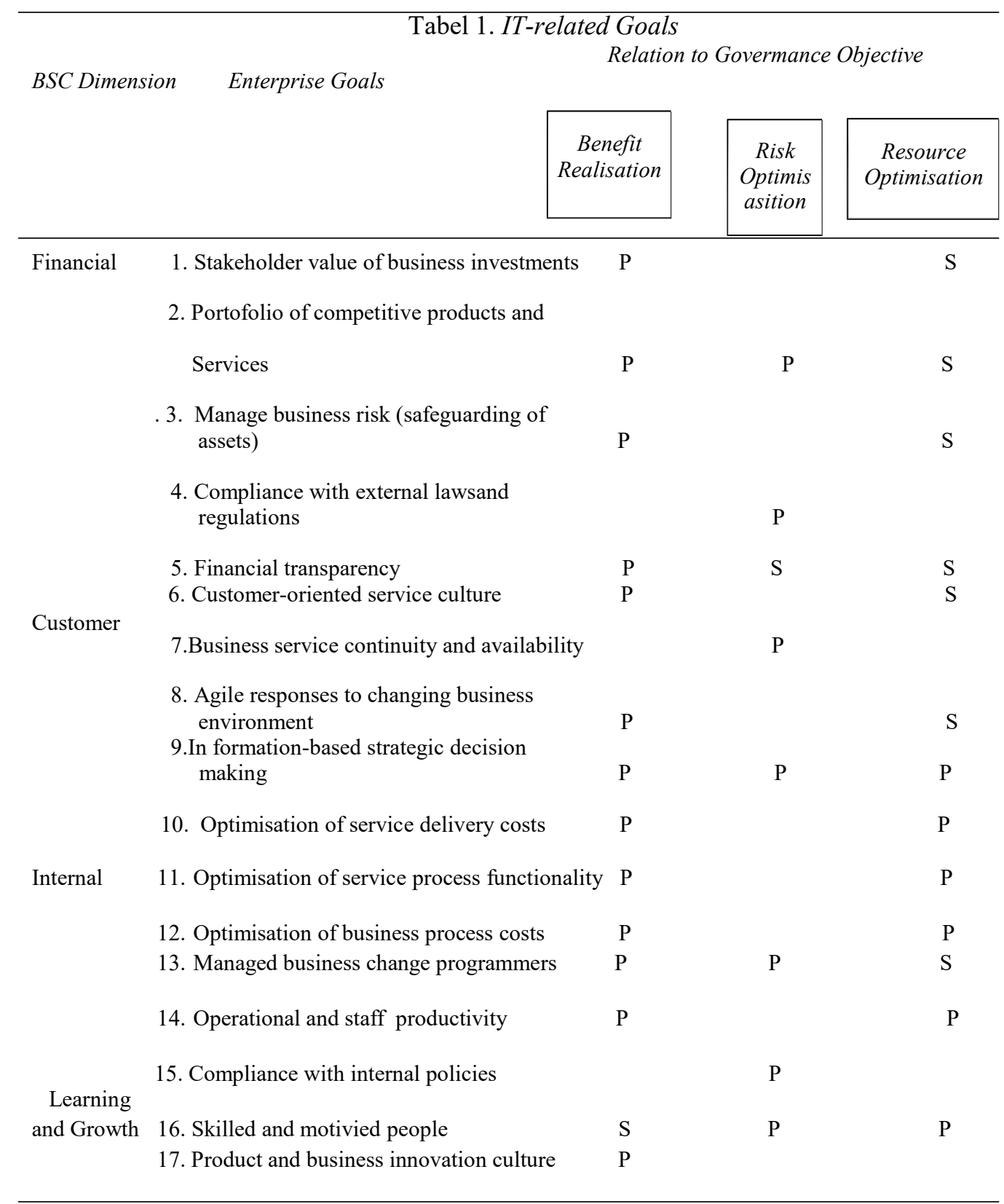

Sumber: ISACA $2012 p$. 
Langkah 3. Enterprise goals to IT-realeted goals.

Pencapaian tujuan perusahaan memerlukan sejumlah IT-realeted yang berhubungan dengan TI, yang diwakili oleh tujuan-tujuan TI. Tujuan-tujuan

yang berhubungan dengan TI disusun dengan dimensi-dimensi dalam IT BSC.

COBIT 5 mendefinisikan 17 tujuan yang berhubungan dengan TI tercantum pada tabel berikut ini :

Tabel 2. IT-related Goals

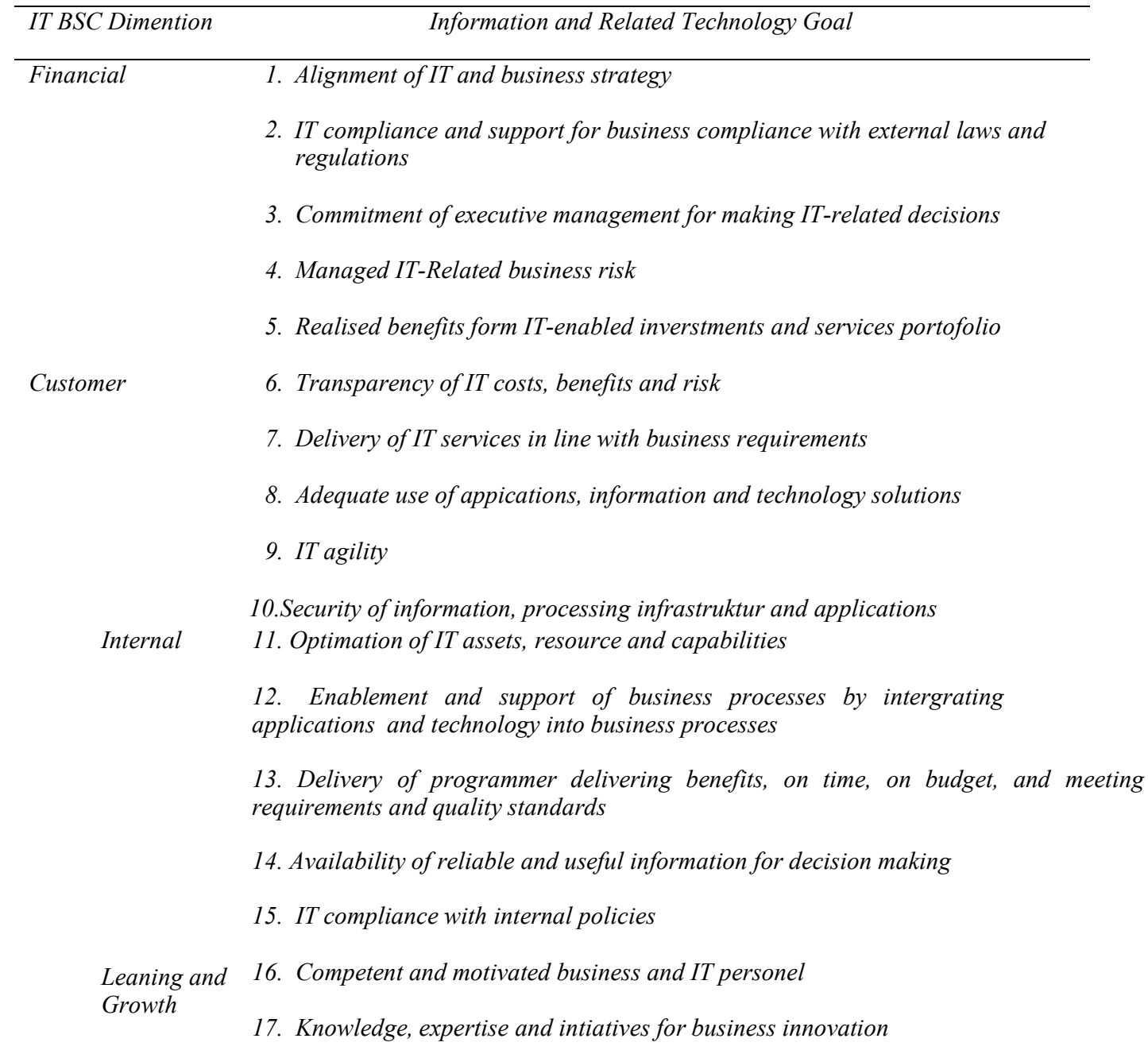


Sumber: ISACA 2012 p.15

\section{Langkah 4. IT $\square$ related goals cascade to enablers goals}

Tujuan TI diturunkan menjadi tujuan pemicu (enabler goal). Mencapai tujuan

TI membutuhkan penerapan yang sukses dan penggunaan sejumlah pemicu. Pemicu meliputi proses, struktur organisasi dan informasi, dan untuk tiap pemicu, serangkaian tujuan yang spesifik dapat didefinisikan untuk mendukung tujuan TI. COBIT 5 memberikan definisi dari proses-proses dalam siklus hidupnya, bersamaan dengan arsitektur yang menggambarkan hubungan antar proses. Proses model referensi COBIT 5 terdiri dari 37 proses menggambarkan siklus hidup untuk tata kelola IT, yang ditunjukan pada gambar dibawah ini

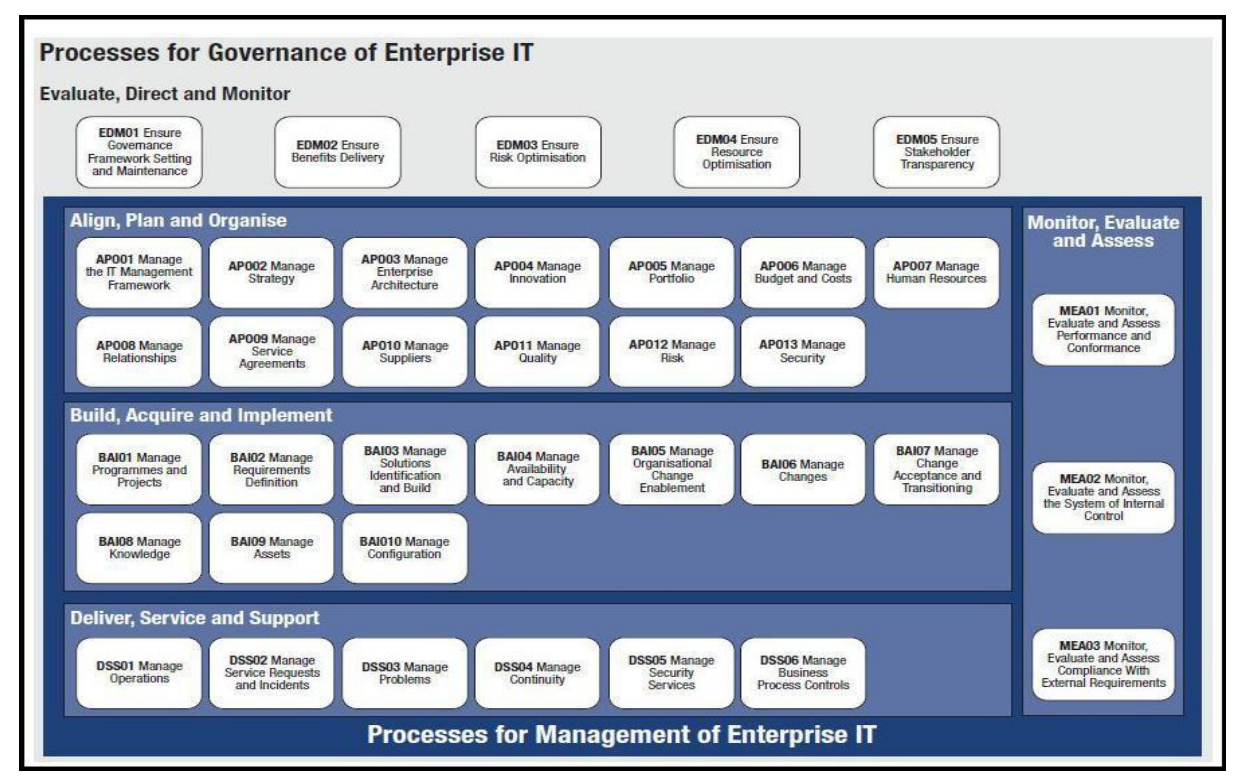

Sumber: ISACA 2012 p.24

\section{Gambar 3. Process Reference Model COBIT 5}

\subsection{Domain dalam COBIT}

Model referensi proses dalam COBIT 5 membagi proses tata kelola dan manajemen TI perusahaan menjadi dua area aktifitas, gorvernance dan management dan ada 5 domain yaitu:

1. Evaluate, Direct, dan Monitor (EDM) : proses pengelolaan yang berhubungan dengan pengelolaan sasaran stakeholder, nilai pengiriman,optimisasi resiko dan sumber daya, termasuk praktek dan aktivitas yang ditujukan pada pengevaluasian pilihan strategi, memberikan pengarahan IT dan pemonitoran outcome.

2. Align, Plan, and Organize (APO) : memberi arahan pada solusi delivery (BAI) dan service delivery and support (DSS). Domain ini mencakup strategi dan taktik, serta berfokus kepada pengidentifikasian cara terbaik pengkontribusian IT untuk pencapaian dari sasaran bisnis.

3. Build, Acquare, and Implement (BAI) : memberikan solusi dan menjadikan pelayanan.

Untuk merealisasikan strategi IT, solusi IT harus diidentifikasi, dikembangkan, atau

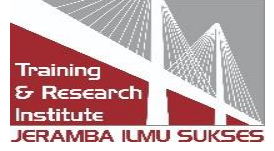


didapatkan begitupun diimplementasikan dan diintegrasikan pada proses bisnis. Perubahan dan maintenance dari sistem yang ada juga dilingkup domain ini, untuk memastikan solusi sesuai dengan tujuan bisnis.

4. Deliver, Service and Support (DSS) : domain ini berfokus dengan aktual delivery and support of required services, yang termasuk service delivery, pengelolaan atas keamanan dan kontinuitas, layanan bantuan untuk users dan manajemen atas data dan fasilitas operasional.

5. Monitor, Evaluate, and Assess (MEA) : memonitor semua proses untuk memastikan pengarahan yang diberikan ditaati. Semua proses IT harus diperiksa secara regular tiap waktu untuk memastikan kebutuhan kualitas dan ketaatan dengan kebutuhan pengendalian. Domain mengajukan manajemen kinerja, monitor dari internal control, ketaatan dan tata kelola yang regular.

\subsection{Definisi Tingkat Kematangan (Maturity Level)}

Maturity model adalah suatu metode untuk mengukur level pengembangan manajemen proses, yang berarti adalah mengukur sejauh mana kapabilitas manajemen tersebut.Seberapa bagusnya pengembangan atau kapabilitas manajemen tergantung pada tercapainya tujuan-tujuan COBIT. Sebagai contoh ada beberapa proses dan sistem kritikal yang membutuhkan manajemen keamanan yang lebih ketat dibanding proses dan sistem lain yang tidak begitu kritikal.

Penerapan yang tepat sistem informasi di suatu lingkungan enterprise, tergantung pada pencapaian tiga aspek maturity (kemampuan, jangkauan dan kontrol). Peningkatan maturity akan mengurangi resiko dan meningkatkan efisiensi, mendorong berkurangnya kesalahan dan meningkatkan kuantitas proses yang dapat diperkirakan kualitasnya dan mendorong efisiensi biaya terkait dengan penggunaan sumber daya sistem informasi .

Maturity model dapat digunakan untuk memetakan :

1. Status pengelolaan sistem informasi perusahaan pada saat itu.

2. Status standart industri dalam sistem informasi saat ini (sebagai pembanding)

3. Status standart internasional dalam sistem informasi saat ini (sebagai pembanding)

4. Strategi pengelolaan sistem informasi perusahaan (ekspetasi perusahaan terhadap posisi pengelolaan sistem informasi perusahaan)

Tingkat kemampuan pengelolaan TI pada skala maturity dibagi menjadi 5 level :

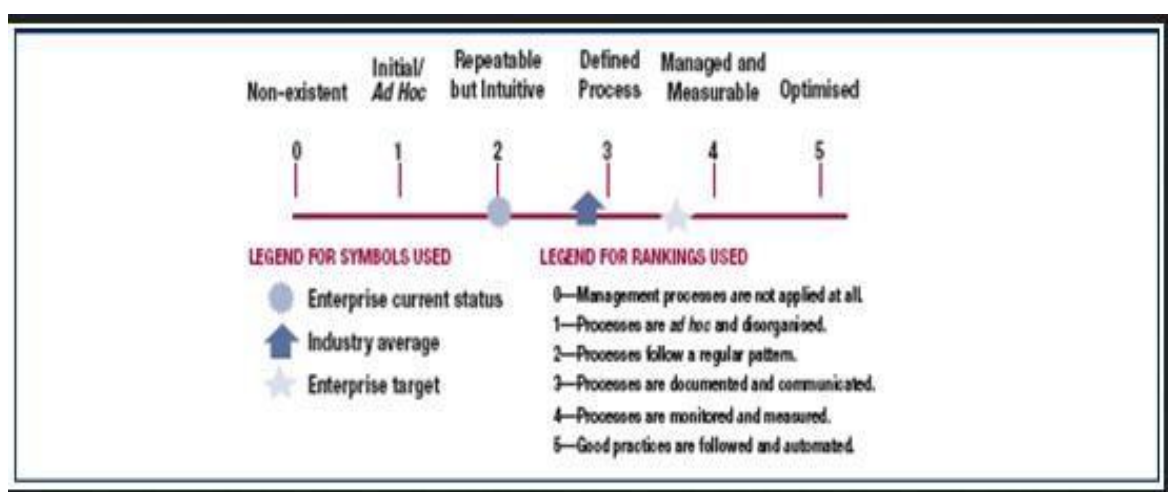


Sumber: ITGI, 2007

Gambar 4 : Urutan Tingkat Kematangan Pengelolaan Sistem Informasi

COBIT 5 merupakan sebuah kerangka menyeluruh yang dapat membantu perusahaan dalam mencapai tujuannya untuk tata kelola dan manajemen TI perusahaan. Secara sederhana, COBIT 5 membantu perusahaan menciptakan nilai optimal dari TI dengan cara menjaga keseimbangan antara mendapatkan keuntungan dan mengoptimalkan tingkat risiko dan penggunaan sumber daya.

COBIT 5 memungkinkan TI untuk dikelola dan diatur dalam cara yang lebih menyeluruh untuk seluruh lingkup perusahaan, meliputi seluruh lingkup bisnis dan lingkup area fungsional TI, dengan mempertimbangkan kepentingan para stakeholder internal dan eksternal yang berhubungandengan TI. COBIT 5 bersifat umum dan berguna untuk segala jenis ukuran perusahaan, baik itu sektor komersial, sektor nonprofit atau pada sektor pemerintahan / public (Antoni, Akbar \& Fatoni, 2018; Antoni, Fikari, Akbar \& Jie, 2018; Akbar \& Antoni, 2019; Ariana, Azim \& Antoni, 2020; Antoni, Jie \& Abareshi, 2020).

Rumah Sakit Ibu dan Anak Hamami adalah salah satu lembaga kesehatan yang melayani masyarakat umum ibu hamil dan anak-anak dalam menangani masalah kesehatan. Rumah sakit ini didirikan oleh Dr. Mustafa Husin Syahab, SpOG pada tanggal 20

September 2009, diresmikan pada tanggal 28 Januari 2010 oleh Kepala Dinas Kesehatan

Kota Palembang. Rumah sakit ini memiliki 7 orang dokter, 14 bidan, 9 perawat, 5 apoteker dan 15 karyawan lainnya. Rumah sakit ini memiliki fasilitas yang cukup lengkap dalam

membantu persalinan ibu-ibu yang akan melahirkan, yaitu memiliki 8 ruang kamar pasien yang memiliki beberapa kelas diantaranya 1 kamar VIP utama, 1 Kamar VIP utama dua,

1 Kamar VIP satu, 1 Kamar VIP dua, 1Kamar Kelas satu , 4 kamar untk kelas dua dan kelas tiga. Selain itu terdapat juga 1 ruang operasi, 2 ruang bersalin, 2 ruang dokter (USG), 1

ruang Unit Gawat Darurat (UGD) dan 1 apotek. RSIA Hamami juga memberikan pelayanan imunisasi setiap awal dan akhir bulannya kepada para balita.

Visi dari RSIA Hamami adalah menjadi lembaga kesehatan yang berguna dalam menyehatkan anak-anak bangsa.

Sedangkan misi dari RSIA Hamami adalah

1. Menyelenggarakan pelayanan kesehatan reproduksi yang paripurna dengan layanan cepat, ramah dan terjangkau oleh masyarakat.

2. Menyelenggarakan pelayanan kesehatan rujukan dan kasus-kasus ibu dan anak baik dari luar rumah sakit maupun rujukan teknis medis dokter spesialis kandungan maupun dokter spesialis anak ke puskesmas.

3. Meningkatkan kualitas dan kuantitas sumber daya manusia yang handal terampil dan religious melalui rekrutmen SDM dan pendidikan formal/ informal.

\section{Metodologi Penelitian}

Pada bagian ini akan dijelaskan mengenai metodelogi yang digunakan oleh penulis dalam penelitian ini. Metodelogi yang merupakan cara dan urutan pengerjaan yang nantinya akan digunakan dalam penelitian ini. Penelitian ini menggunakan metode analisis deskriptif

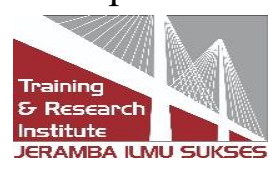


kualitatif (Fauzi, Dencik \& Asiati, 2019).

Selain itu metodelogi juga menentukan output yang diharapkan dari setiap masukan

yang ada. Tujuan dari metodelogi dari penelitian ini adalah agar proses yang ada menjadi lebih teratur dan sistematis. Selain itu diharapkan mempermudah perkembangan dan tingkat keberhasilan dari makalah yang di buat, Adapun langkah-langkah yang akan dilakukan dalam penelitian ini meliputi tahapan studi pustaka, wawancara, kuesioner dan analisis serta pembahasan.

\section{a. Studi Pustaka}

Studi Pustaka dilakukan dengan melakukan beberapa teori, pencarian referensi jurnaljurnal penelitian untuk menunjang data sekunder, baik lewat internet tentang COBIT 5 yang menyangkut dalam pembuatan penelitian serta melakukan analisa dan perbandingan terhadap teori yang didapat.

b. Wawancara (Interview)

Pengumpulan data dilakukan dengan mengadakan tanya jawab secara langsung dengan wakil pimpinan RSIA Hamami.

c. Kuesioner

Pembuatan kuesioner bertujuan untuk menetapkan domain proses pada COBIT 5 secara garis besar. Penulis memberikan daftar pertanyaan kepada pimpinan rsia, wakil pimpinan rsia, sekertaris rsia, kepala keuangan, wakil keuangan, kepala ruangan, wakil ruangan, kepala administrasi, kepala server dan kepala apotek sebagai responden. Dari daftar pernyataan tersebut jawaban akan ditabulasi berdasarkan pernyataan untuk semua divisi.

Berdasarkan data yang telah dikumpulkan, maka kemudian data tersebut di evaluasi dengan tahapan sebagai berikut :

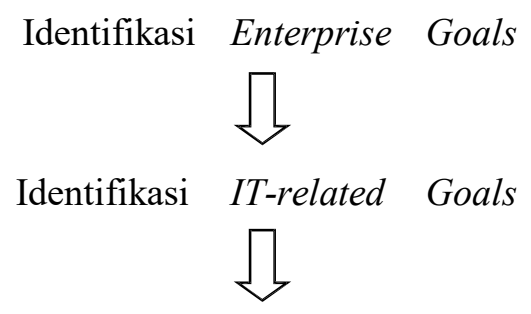

Identifikasi Enabler Goals<smiles>C1=CC=C1</smiles>

Maturity Level

\section{Hasil dan Pembahasan}

Pada tahap ini akan di definiskan Enterprise Goals yang berlaku di COBIT 5.0 yang diselaraskan dengan tujuan bisnis dari rumah sakit. Pada Enterprise Goals ini hanya berfokus pada sumber daya optimasi. Hal yang pertama kali dilakukan pada tahap ini adalah

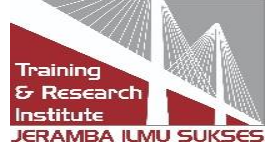


mengidentifikasi tujuan bisnis dan sasaran RSIA Hamami, yaitu :

Tabel 3. Pemetaan Enterprise Goals

\begin{tabular}{llc} 
& \multicolumn{1}{c}{ Tujuan perusahaan dipetakan ke governance } & \\
BSC Dimension & \multicolumn{1}{c}{ Tujuan } & Sumber Daya Optimasi \\
\hline Pelanggan & 9. Informasi Berbasis Pengambilan Keputusan Strategis & $\mathbf{P}$ \\
Internal & 11.Optimasi Fungsi Proses Bisnis & $\mathbf{P}$ \\
Belajar\& Pertumbuhan & 16.Orang yang terampil dan terinovasi & $\mathbf{P}$
\end{tabular}

Setelah mengidentifikasi Enterprise Goals langkah selanjutnya adalah mengidentifikasi

IT-related Goals yang sesuai dengan sttudi kasus. Berdasarkan Enterprise Goals COBIT

5.0 diatas maka kita dapat melihat IT-Related Goals apa saja yang sesuai dengan RSIA Hamami seperti dalam tabel dibawah ini :

Tabel 4. Pemetaan IT-Related Goals

\begin{tabular}{|c|c|c|c|c|}
\hline \multicolumn{5}{|c|}{ Pemetaan COBIT 5 tujuan RSIA Hamami untuk tujuan yang berkaitan dengan IT } \\
\hline & & & Tujuan Peru & \\
\hline \multirow{3}{*}{\multicolumn{2}{|c|}{ Tujuan kegiatan IT }} & $\begin{array}{l}\text { Informasi } \\
\text { berbasis } \\
\text { pengambilan } \\
\text { keputusan } \\
\text { strategis }\end{array}$ & $\begin{array}{l}\text { Optimasi Proses } \\
\text { Bisnis }\end{array}$ & $\begin{array}{l}\text { Orang Terampil } \\
\text { dan Termotivasi }\end{array}$ \\
\hline & & 9 & 11 & 16 \\
\hline & & Customer & Internal & Belajar \& Pertumbuhan \\
\hline Financial & $\begin{array}{l}\text { 1.Penyelarasan IT dan strategis } \\
\text { Bisnis }\end{array}$ & $\mathbf{P}$ & $\mathbf{P}$ & \\
\hline \multirow[t]{2}{*}{ Customer } & $\begin{array}{l}\text { 7. Layanan sesuai dengan Kebutuhan } \\
\text { Bisnis }\end{array}$ & & $\mathbf{P}$ & \\
\hline & $\begin{array}{l}\text { 8. Penggunaan memada aplikasi, } \\
\text { informasi dan solusi teknologi }\end{array}$ & & $\mathbf{P}$ & \\
\hline Internal & $\begin{array}{l}\text { 9. Optimalisasi Aset IT, sumber } \\
\text { daya dan kemampuan } \\
\text { 12. Pemberdayaan dan dukungan } \\
\text { dari proses bisnis dengan aplikasi } \\
\text { yang terpadu dan info teknologi } \\
\text { proses bisnis }\end{array}$ & $\mathbf{P}$ & $\begin{array}{l}\mathbf{P} \\
\mathbf{P}\end{array}$ & \\
\hline $\begin{array}{c}\text { Belajar \& } \\
\text { Pertumbuhan }\end{array}$ & $\begin{array}{l}\text { 14. Ketersedian Handal dan } \\
\text { Informasi berguna untuk } \\
\text { pengambilan keputusan } \\
\text { 16. Bisnis yang kompeten, } \\
\text { terinovasi dan personil IT }\end{array}$ & & & $\mathbf{P}$ \\
\hline
\end{tabular}


Tujuan sistem informasi diturunkan menjadi pemicu (enabler goals). Mencapai tujuan sistem informasi membutuhkan penerapan yang sukses dan acuan sebagai tujuan organisasi. Hasil dari enaber goals akan menjadi acuan pembuatan kuesioner untuk mengukur tingkat kematangan penggunaan sumber daya sistem informasi yang ada di RSIAHamami.

Tabel 5. Enabler Goals

\begin{tabular}{|c|c|c|}
\hline Proses COBIT 5.0 & Tujuan RSIA Hamami & \\
\hline EDM 04 & Memastikan Pengoptimalan sumber daya & $\mathrm{P}$ \\
\hline APO 09 & Mengelola persetujuan dan layanan & $\mathrm{P}$ \\
\hline DSS 02 & Mengelola permintaan service/layanan & $\mathrm{P}$ \\
\hline MEA 01 & $\begin{array}{l}\text { Memonitor, Mengevaluasi dan mengukur } \\
\text { Kinerja dan kesesuaian }\end{array}$ & $\mathrm{P}$ \\
\hline
\end{tabular}

Maturity Level adalah suatu metode untuk mengukur level pengembangan manajemen proses, yang berarti adalah mengukur sejauh mana kapabilitas manajemen tersebut. Seberapa bagusnya pengembangan atau kapabilitas manajemen tergantung pada tercapainya tujuantujuan COBIT. Penilaian Maturity level pada setiap domain sebagai berikut :

1. Domain proses EDM04 (pengelolaan sumber daya)

Dari hasil penilaian terhadap pernyataan EDM04 didapatkan tingkat kematangan :

Tabel 6. Tingkat kematangan domain proses

\begin{tabular}{|c|c|}
\hline \multicolumn{2}{|c|}{ EDM04 } \\
\hline Pertanyaan kuesioner & Tingkat Kematangan \\
\hline EDM 04.x & 3,60 \\
\hline EDM 04. $\mathrm{x}_{2}$ & 3,70 \\
\hline EDM 04. ${ }_{3}$ & 3,50 \\
\hline EDM 04. $x_{4}$ & 3,60 \\
\hline EDM 04.X5 & 3,30 \\
\hline Maturity Level & 3,54 \\
\hline
\end{tabular}

Tingkat kematangan dari penilaian terhadap 10 responden pada domain proses EDM 04 yaitu 3,54. Hal tersebut berdasarkan 5 pertanyaan yang diajukan peneliti terhadap responden. Tingkat kematangan 3,54 menunjukan defined process yaitu proses sudah berhasil dijalankan namun harus diikuti dan disosialisasikan. Prosedurnya kurang lengkap namun dapat dilakukan apabila telah disosialisasikan dengan baik.

2. Domain APO09 ( mengelola persetujuan dan layanan)

Dari hasil penilaian terhadap pernyataan APO09 didapatkan tingkat kematangan :

Tabel 7. Tingkat kematangan domain proses

Pertanyaan kuesioner

\section{APO09}

\begin{tabular}{|c|c|}
\hline APO 09. $x_{1}$ & 3,70 \\
\hline APO 09. $x_{2}$ & 3,40 \\
\hline APO 09. ${ }_{3}$ & 3,40 \\
\hline APO 09. $x_{4}$ & 3,50 \\
\hline
\end{tabular}




\section{Jo JPSII \\ p-ISSN $x x x x-x x x x$, e-ISSN: $x x x x-x x x x$ Vol. 1, No. 1, Agustus 2020 \\ APO 09.X5 \\ Maturity Level \\ 3,40 \\ 3,48}

Tingkat kematangan dari penilaian terhadap 10 responden pada domain proses APO 09 yaitu 3,48. Hal tersebut berdasarkan 5 pertanyaan yang diajukan peneliti terhadap responden. Tingkat kematangan 3,48 menunjukan defined process yaitu proses sudah berhasil dijalankan namun harus diikuti dan disosialisasikan. Prosedurnya kurang lengkap namun dapat dilakukan apabila telah disosialisasikan dengan baik.

3. Domain Proses DSS02 (mengelola permintaan service atau layanan)

Dari hasil penilaian terhadap pernyataan DSS 02 didapatkan tingkat kematangan:

Tabel 8. Tingkat Kematangan Domain proses

\begin{tabular}{|c|c|}
\hline & \\
\hline Pertanyaan kuesioner & Tingkat kematangan \\
\hline DSS 02. $x_{1}$ & 3,50 \\
\hline DSS 02. $x_{2}$ & 3,20 \\
\hline DSS 02. $x_{3}$ & 3,40 \\
\hline DSS 02.x 4 & 2,90 \\
\hline DSS 02.X5 & 3,00 \\
\hline Maturity Level & 3,20 \\
\hline
\end{tabular}

Tingkat kematangan dari penilaian terhadap 10 responden pada domain proses DSS 02 yaitu 3,20. Hal tersebut berdasarkan 5 pertanyaan yang diajukan peneliti terhadap responden. Tingkat kematangan 3,20 menunjukan defined process yaitu proses sudah berhasil dijalankan namun harus diikuti dan disosialisasikan. Prosedurnya kurang lengkap namun dapat dilakukan apabila telah disosialisasikan dengan baik.

4. Domain Proses MEA 01 (Memantau, Mengevaluasi, Menilai Kinerj dan Kesesuaian) Dari hasil penilaian terhadap pernyataan MEA 01 didapatkan tingkat kematangan :

Tabel 9. Tingkat Kematangan Domaim Proses

\begin{tabular}{|c|c|}
\hline \multicolumn{2}{|c|}{ MEA01 } \\
\hline Pertanyaan kuesioner & Tingkat kematangan \\
\hline MEA 01. $x_{1}$ & 3,10 \\
\hline MEA 01. $x_{2}$ & 3,20 \\
\hline MEA 01.x 3 & 3,40 \\
\hline MEA 01. $x_{4}$ & 3,40 \\
\hline MEA 01.X5 & 3,10 \\
\hline Maturity Level & 3,24 \\
\hline
\end{tabular}

Tingkat kematangan dari penilaian terhadap 10 responden pada domain proses MEA 01 yaitu 3,24. Hal tersebut berdasarkan 5 pertanyaan yang diajukan peneliti terhadap responden. Tingkat kematangan 3,24 menunjukan defined process yaitu proses sudah berhasil dijalankan namun harus diikuti dan disosialisasikan. Prosedurnya kurang lengkap namun dapat dilakukan apabila telah disosialisasikan dengan baik. 
Berdasarkan hasil penilaian dari setiap domain proses dapat disimpulkan bahwa tingkat kematangan tertinggi domain proses yaitu EDM04 (pengelolaan sumber daya) yaitu 3,54 yang berada pada level defined process. Tingkat kematangan kedua setelah EDM04 adalah APO09 (mengelola persetujuan dan layanan) yaitu pada level 3,48 yang berada pada level defined process.

Tingkat kematangan ketiga setelah APO09 adalah domain MEA 01 (memantau, mengevaluasi, menilai kinerja dan kesesuaian) yaitu 3,24 yang berada pada level defined process. Sedangkan untuk tingkat kematangan terendah adalah DSS02 (mengelola permintaan service atau layanan) yaitu pada level 3,20 yaitu yang berada pada level defined process dapat dilihat pada tabel dibawah ini :

Tabel 10. Maturity Level

\begin{tabular}{clc} 
Proses COBIT 5.0 & \multicolumn{1}{c}{ Tujuan RSIA Hamami } & Maturity Level \\
\hline EDM 04 & Memastikan Pengoptimalan sumber daya & 3,54 \\
APO 09 & Mengelola persetujuan dan layanan & 3,48 \\
DSS 02 & Mengelola permintaab service/layanan & 3,20 \\
MEA 01 & Memonitor, Mengevaluasi dan mengukur & 3,24
\end{tabular}

Berdasarkan perhitungan kematangan diatas, dapat dilihat bahwa RSIA Hamami berada pada kisaran 3,36 untuk keseluruhan tingkat kematangan. Hal ini berarti RSIA Hamami sudah mencapai tingkat best practice yang ditunjukan pada gambar dibawah ini:

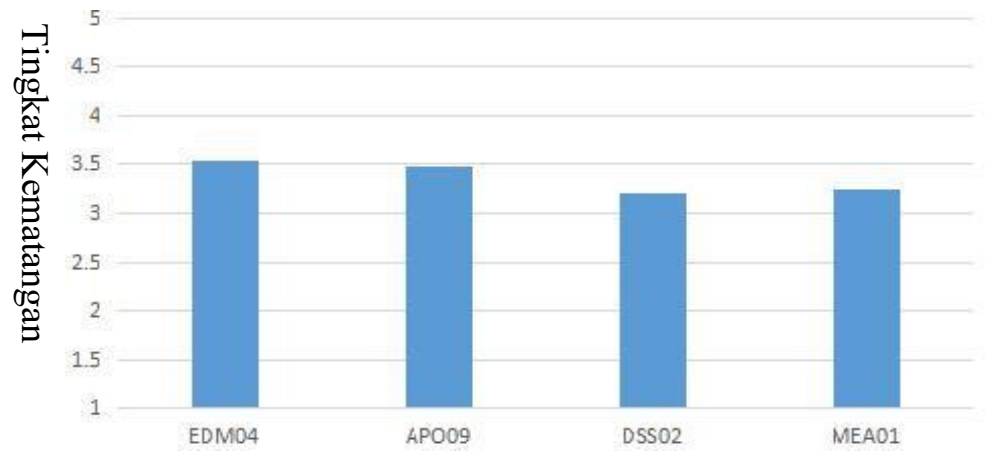

Gambar 5. Grafik Tingkat Kematangan

Berikut ini grafik jaring laba-laba pada setiap domain :

\section{TINGKAT KEMATANGAN}

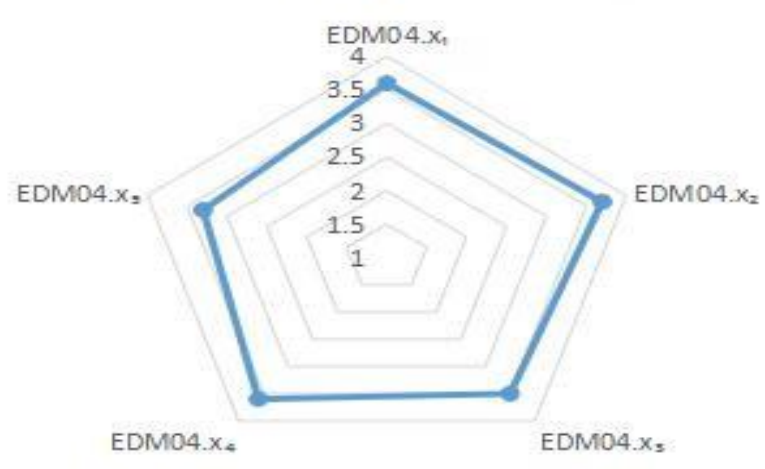


Gambar 6. Grafik Tingkat Kematangan Pada Domain EDM 04

\section{TINGKAT KEMATANGAN}

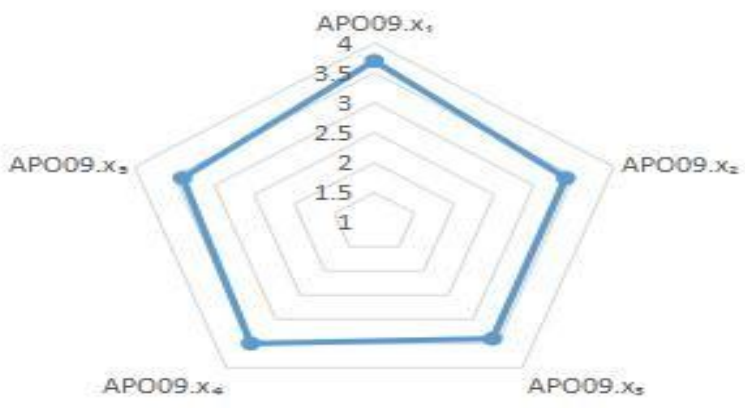

Gambar 7. Grafik Tingkat Kematangan Pada Domain APO09 TINGKAT KEMATANGAN

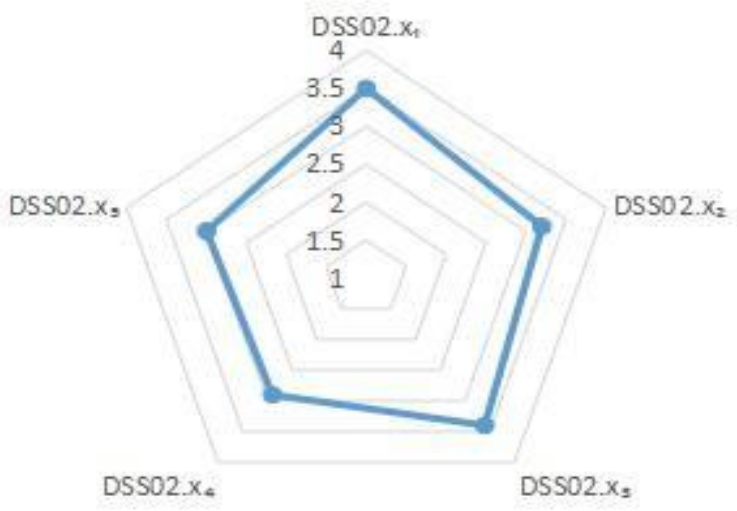

Gambar 8. Grafik Tingkat Kematangan Pada Domain DSS02

\section{TINGKAT KEMATANGAN}

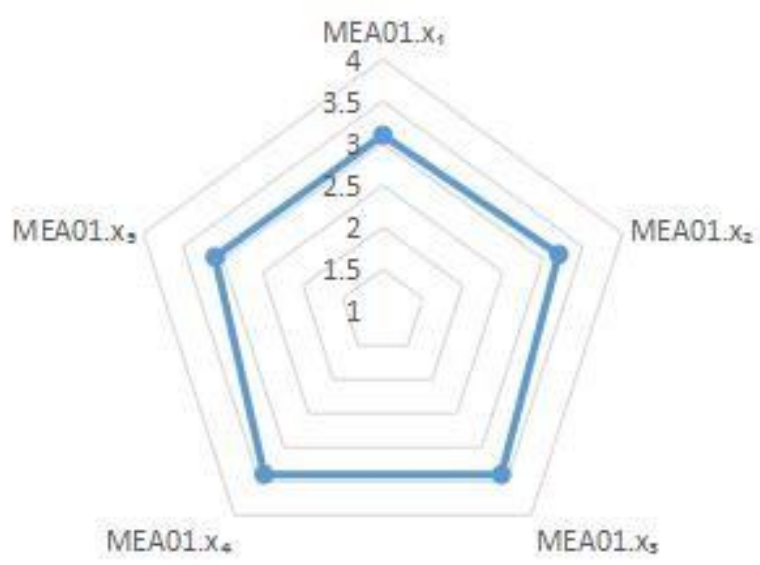

Gambar 9. Grafik Tingkat Kematangan Pada Domain MEA01

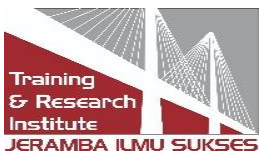




\section{Kesimpulan}

Berdasarkan hasil analisis dan evaluasi yang telah dibahas dalam bab 4, maka kesimpulan yang bisa penulis peroleh adalah :

1. Analisa dari visi dan misi RSIA Hamami menghasilkan tujuan perusahaan di petakan ke governace berfokus pada sumber daya optimisasi dan berfokus pada data yang primer. Domain yang digunakan yaitu informasi berbasis pengambilan keputusan, optimisasi fungsi proses bisnis, dan orang yang terampil dan termotivasi.

2. Analisa pemanfatan tingkat kematangan sistem informasi Pada RSIA

3. Hamami. Domain yang digunakan Evaluate, Direct and Monitor (EDM) prosenya yaitu EDM04, Align,Plan and Organise (APO) prosesnya yaitu APO09, Deliver, Service and Support (DSS) prosesnya yaitu DSS02, Monitor, Evaluate, and Assess (MEA) prosesnya yaitu MEA01.

4. Berdasarkan hasil penilaian dari setiap domain proses dapat disimpulkan bahwa tingkat kematangan tertinggi domain proses yaitu EDM04 (pengelolaan sumber daya) yaitu

3,54 yang berada pada level defined process. Tingkat kematangan kedua setelah

EDM04 adalah APO09 (mengelola persetujuan dan layanan) yaitu pada level 3,48yang berada pada level defined process. Tingkat kematangan ketiga setelah APO09 adalah domain MEA 01 (memantau, mengevaluasi, menilai kinerja dan kesesuaian) yaitu 3,24 yang berada pada level defined process. Sedangkan untuk tingkat kematangan terendah adalah DSS02 (mengelola permintaan service atau layanan) yaitu pada level 3,20 yaitu yang berada pada level defined process.

5. Berdasarkan analisis dengan menggunakan metode COBIT 5.0 yang dilakukan pada sistem informasi di RSIA Hamami menghasilkan nilai maturity level 3 yaitu dimana

RSIA Hamami telah memilki pola yang berulang kali dalam melakukan manajemen aktivitas terkait dengan sistem informasi, namun keberadannya belum terdefinisi dengan baik. Walaupun sudah mulai ada prosedur namun tidak seluruhnya terdokumentasi dan tidak seluruhnya disosialisasikan kepada pegawai sehingga tanggung jawab pelaksanaan proses kerja berada pada masing-masing individu, level tersebut sudah cukup baik namun belum mencapai nilai optimal dalam penilaian metode COBIT 5.0.

\section{Referensi}

Akbar, M., \& Antoni, D. (2019). E-supply chain management value concept for the palm oil industry. Jurnal Sistem Informasi, 15(2), 15-29.

Antoni, D., Akbar, M., \& Fatoni, F. (2018). Electronic government Rukun Tetangga model. Jurnal Sistem Informasi, 14(2), 64-73.

Antoni, D., Fikari, D., Akbar, M., \& Jie, F. (2018). The readiness of palm oil industry in enterprise resource planning. Telkomnika, 16(6).

Antoni, D., Jie, F., \& Abareshi, A. (2020). Critical factors in information technology capability for enhancing firm's environmental performance: Case of Indonesian ICT sector. International Journal of Agile Systems and Management, 13(2), 15-181.

Ariana, S., Azim, C., \& Antoni, D. (2020). Clustering of ICT human resources capacity in the 
implementation of E-government in expansion area: A case study from Pali regency. Cogent Business \& Management, 7(1), 1754103.

Fauzi, F., Dencik, A. B., \& Asiati, D. I. (2019). Metodologi Penelitian Untuk Manajemen dan Akuntansi. Jakarta: Salemba Empat.

ISACA. (2012). Enabling Process. ISACA.

ITGI. (2007). Framework Control Objectives Management Guidelines Maturity Models.

Jogiyanto. (1999). Analisis dan Desain Sistem Informasi : Pendekatan Terstruktur Teori dan

Kadir, A. (2003). Pengenalan Sistem Informasi. Andi, Yogyakarta.

Praktek Aplikasi Bisnis, ANDI Yogyakarta. Yogyakarta.

\section{Copyrights}

Copyright for this article is retained by the author(s), with first publication rights granted to the journal.

This is an open-access article distributed under the terms and conditions of the Creative Commons Attribution license (http://creativecommons.org/licenses/by/4.0/) 